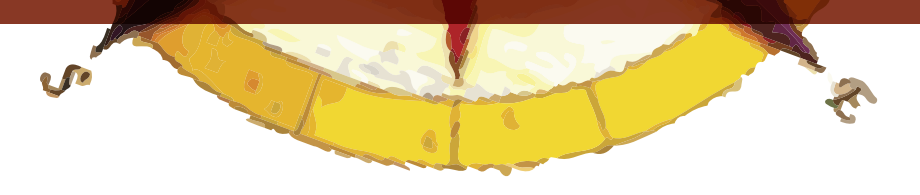

\title{
LUGAR E COTIDIANO NUM DIÁLOGO COM AS POLÍTICAS PÚBLICAS: O INDIVIDUAL E O COLETIVO EM EDUCAÇÃO
}

\author{
Adriana Maria Andreis ${ }^{1}$
}

\section{RESUMO}

$\mathrm{Na}$ interlocução entre os significantes peculiares de cada sujeito, constituídos como lugar e cotidiano, abrigo uma reflexão que tensiona as diferenças singulares e as proposições generalizantes das políticas públicas. Estas, como projetos de Estado, carregam uma dimensão globalizante que é apresentada a um coletivo, o que, numa análise mais apressada, parece se contrapor à singularidade e originalidade de cada sujeito. Nesse sentido, neste artigo, apresento um ensaio teórico que tem a pretensão de pensar essa relação individualidade e coletividade tendo como pano de fundo da reflexão as políticas na educação. Uma argumentação que envolve os desafios e possibilidades subjetivas, mas que assume a linguagem como elemento central na constituição do sujeito, processo que acontece de forma intersubjetiva. Analiso, dessa forma, o espaço como pressuposto para pensar o individual e o coletivo, o papel fundamental das categorias geográficas cotidiano e lugar na vida do sujeito, que está sujeito às políticas públicas, e encaminho discutindo o processo das políticas que são elaborações que abrangem grupos, pois são públicas, no contexto de sujeitos que são singulares. Proponho que, organizar políticas públicas para sujeitos singulares, pode encontrar na educação escolar, um aliado. Isso, porque dependendo do modo como é encaminhado, o processo educativo pode contribuir para a constituição de um sujeito autônomo e emancipado, porque e desde que, auxilie construindo compreensões considerando relações escalares, que reconheçam o local e global e que oportunizem a ressignificação do mundo da vida.

Palavras-chave: Espaço. Categorias geográficas. Sujeito. Local-global. Subjetividade e intersubjetividade.

\section{RESUMEN}

En la interlocución entre los significantes peculiares de cada sujeto, constituidos como lugar y

1 Professora de Geografia na Universidade Federal da Fronteira Sul - UFFS - em Chapecó/SC. Doutora em Educação nas Ciências: concentração Geografia, pela UNIJUI, Ijuí/RS e UAM, Madrid, Espanha. 
cotidiano, hago una reflexión que acentúa la singularidad y las propuestas generalizadoras de las políticas públicas. Éstas, como proyectos del Estado, tienen una dimensión globalizadora y son presentadas al colectivo; que en un análisis más superficial, parece contrarrestar la originalidad y singularidad de cada sujeto. En este sentido, en este artículo, presento un ensayo teórico que pretende pensar esta relación, individualidad y colectividad, como políticas de fondo a la reflexión sobre la educación. Una argumentación que implica retos y posibilidades subjetivas, pero que asume el lenguaje como un elemento central en la constitución del sujeto, es decir, es un proceso que se lleva a cabo de manera intersubjetiva. Analizo, por lo tanto, el espacio como presuposición indispensable para pensar lo individual y lo colectivo, el papel fundamental de las categorías geográficas; cotidiano y lugar en la vida del individuo que depende de las políticas públicas, y el avance en el proceso de reflexión sobre las políticas que son elaboraciones que abarcan grupos porque son públicas, en el contexto de los individuos que son únicos. Propongo que organizar las políticas públicas para los sujetos singulares puede encontrar en la educación escolar, un aliado. Esto porque, dependiendo de la forma en que se conduzca el proceso educativo, éste puede contribuir al establecimiento de un sujeto autónomo emancipado porque y desde que ayude a la construcción de entendimientos, teniendo en cuenta las relaciones escalares que reconozca qué es local y qué es global y, también, que favorezcan el replanteamiento del mundo de la vida.

Palabras clave: Espacio. Categorías geográficas. Sujeto. Local- global. La subjetividad y la intersubjetividad.

\section{ABSTRACT}

In the dialogue between peculiar signifiers of each people as subjects, which are constituted as the place and the everyday life, I think about a reflection which strains the natural differences and generalizing propositions of the public policies. These topics, as projects of State, carry a global dimension that is collective, in which, in a more cursory analysis, it seems to counteract to the uniqueness and originality of each subject. Accordingly, in this article, I present a theoretical essay that purports to think about this relationship between individuality and collectivity as background reflection policies on education. It is an argument that involves challenges and subjective possibilities, but that takes the language as a core element in the constitution of the subject, it is a process that takes place in an intersubjective way. I analyze, thus the space as a prerequisite for the individual and collective thinking, the fundamental role of the everyday life and the place in the subject geographical categories, which is the subject of the public policy, and I forward the process of discussion of the policies that are elaborations covering groups because they are public, in the context of individuals who are natural ones. I propose that, if we organize the public policies for singular subjects, we can find an ally in the school education. This thing occurs because I depend on how it is sent by itself, the educational process can contribute to the establishment of an autonomous and emancipated subject because and since, it could assist the constructions of the understandings considering the scalar relationships and also recognize the local and global opportunity and signification of the world of life.

Keywords: Space. Geographical categories. Subject. Local-global. Subjectivity and Intersubjectivity. 


\section{CONSIDERAÇÕES INICIAIS}

"[...] Das margens se veem melhor as estruturas de poder" (B. Santos, 2007, p. 59).

$\mathrm{Na}$ interlocução entre os significantes peculiares de cada sujeito, constituídos como lugar e cotidiano, abrigo uma reflexão que tensiona as diferenças individuais e as proposições generalizantes aos coletivos, representadas pelas políticas públicas. Nesta reflexão, que tem como pano de fundo a educação, coloco em questão os projetos de Estado, que carregam uma dimensão globalizante, na medida em que são apresentados à coletividade, o que, numa análise mais apressada, parece se contrapor à singularidade e originalidade dos sujeitos.

Apesar da "sensação difusa de que a vida real está em outro lugar ou em lugar nenhum" (Stam, 2000, p. 49-61), os eventos da vida com os quais as pessoas interagem em seu plexo de relações, estão permanente e obrigatoriamente em contato com objetos e ações em algum e com algum local do espaço. Essa assertiva sugere a relevância de uma discussão que considere essa condição, abrindo à reflexão acerca da importância de pensar sobre a singularidade do sujeito no contexto das políticas públicas em educação.

Não apenas cada sujeito é singular. Também, cada contexto com o qual se envolve como, por exemplo, a escola, também é sempre singular. Envolve cada um e todos os sujeitos, constituições, impressões e expressões históricas latentes peculiares e que é importante serem ponderadas na relação com as proposições coletivas em educação. Embora todos estejam implicados na analise que apresento, referirei o sujeito, pensando especialmente no aluno e no professor, enfocados pelo cotidiano e lugar.

Para desencadear a discussão, movida pela interrogação acerca da relação entre a individualidade e a coletividade ${ }^{2}$ na educação, construo inicialmente um tecido argumentativo que apresenta e distingue as categorias lugar e cotidiano pelo viés da espacialidade. Dessa tessitura, em seguida, fomento a análise sobre a relevância dessas instâncias aos sujeitos no processo educativo, tendo como horizonte a aposta reflexiva que realizo posteriormente, numa aporia que envolve as políticas públicas em educação.

Deixo claro que a pretensão neste texto não carrega um tratamento de contraposição e defesa, nem mesmo de proposição de alternativas para a questão lançada, ou seja, para a aparente dicotomia entre a singularidade do sujeito e a globalidade das políticas de Estado. Como pesquisadora da área da Geografia envolvida com investigações que trazem imbricadas a compreensão da fundamentalidade do cotidiano e do lugar nos processos de significação dos conhecimentos, o que proponho é o fomento da reflexão no processo de mediação das individualidades com as proposições públicas em educação. Discussão pertinente, porque efetivamente os planos públicos, que carregam um objetivo de inserção ampla e geral, focam eminentemente o coletivo, e, se fazem presentes na escola e na vida de professor, e, assim na vida dos alunos.

2 A instituição escolar tem como característica fundamental a reunião de um coletivo em cada sala de aula. Esta estrutura é também fundamental nos processos que envolvem o ensinar e o aprender. Mas, aqui trato especialmente de uma compreensão do coletivo que é arranjada como organização pública e estatal. 


\section{ESPAÇO COMO PRESSUPOSTO PARA PENSAR O INDIVIDUAL E O COLETIVO}

Apoio-me em Bakhtin (2010) para enunciar a compreensão que abriga o argumento da centralidade de uma análise que escancara a singularidade do sujeito, único, excepcional, incomparável e irrepetível.

Neste preciso ponto singular no qual agora me encontro, nenhuma outra pessoa jamais esteve no tempo singular e no espaço singular de um existir único. E é ao redor deste ponto singular que se dispõe todo o existir singular de modo singular e irrepetível (Bakhtin, 2010a, p. 96).

Essa condição única é vivida apenas por um sujeito naquele momento e local, ou seja, é espacializada, realiza-se na relação com o lugar de vida dos sujeitos. A construção da compreensão de cada uma é, assim, uma elaboração singular e provisória. Paralelamente a aprendizagem decorrente das vivências nas mais diversas dimensões, é também, sempre uma criação original dependente do mundo da vida, que envolve o cotidiano e o lugar de cada sujeito. Bakhtin (2004) também permite pensar sobre a espacialidade como elemento constitutivo do aprender ao afirmar que "compreendemos as palavras e somente reagimos àquelas que despertam em nós ressonâncias ideológicas ou concernentes à vida" (p. 95).

Merleau-Ponty ${ }^{3}$ (1971), embora realize uma análise com outra perspectiva, permite refletir sobre as possibilidades do mundo da vida, e daí, a inegável constituição única, pois, afirma que, "tudo o que sei de mundo, mesmo devido à ciência, o sei a partir de minha visão pessoal ou de uma experiência do mundo sem a qual os símbolos da ciência nada significariam" (p. 6). Ou seja, "[...] não pensa que se possa compreender o homem e o mundo de outra forma senão a partir de sua "facticidade"”. (id. p.5).

Marques (2000) também alicerça as compreensões que tem o sujeito e sua vida como centro das possibilidades, ao afirmar que se coloca "o mundo da vida como anterioridade primeira, onde se alicerçam as aprendizagens e se efetivam e onde radica, em sua unidade, o processo de socialização/ individuação e da singularização do sujeito" (p. 19). Sendo, o mundo da vida, a dimensão na qual o existir como evento singular é definível apenas "pelas categorias da participação real, isto é, do ato, pelas categorias do efetivo experimentar operativo e participativo da singularidade concreta no mundo" (Bakhtin, 2010, p. 59), a questão que apresento se refere à relevância das políticas publicas em educação, levarem em conta essa condição analisada por Bakhtin.

Postas algumas ponderações sobre a importância de considerar a vida dos sujeitos e suas possibilidades no ensino de conhecimentos e conceitos científicos nos processos de aprender nas diferentes áreas do conhecimento, assumo a espacialidade como percurso da análise, porque permite uma compreensão de que não apenas estamos no espaço, mas, de que somos o espaço. Falar de espaço é falar da vida das pessoas, pois é possível falar em vida humana apenas se considerarmos a espacialidade. O espaço é resultado e resulta no modo como somos. Essa interpretação é um processo de construir conhecimentos sobre o que somos e como somos tanto individual como coletivamente.

Nessa compreensão de espaço, oriento a discussão usando as categorias que tem como centro as relações que se processam concreta e diariamente entre todos os sujeitos, ou seja, cotidiano e lugar.

3 Resguardadas compreensões teóricas outras - do viés fenomenológico, por exemplo, que não toma parte neste texto. 
Sempre espacializadas, essas dimensões geográficas constituem os sujeitos, que por sua vez as constituem interativamente, pelas compreensões construídas, sujeitos de natureza social, mas que são singulares e que com/vivem coletivamente.

É uma dimensão pensada como grande escala, que atribui centralidade ao sujeito que se constitui, constrói e é constituído implicado em cotidiano e lugar. Essa proximidade de significados permite compreender elementos e ações concretas, especialmente do contexto da individualidade e põe acento na subjetividade. Uma dimensão que esmaece a visualização do todo, por isso, traz a latente a exigência da análise com abrangência mais ampla. A visão global é a pequena escala, mas, contém sempre um grau maior de esmaecimento de muitos e a saliência de poucos elementos pré-selecionados. Trata-se de uma percepção generalizante dos sistemas mais abrangentes, o que é também importante, porque, permite compreender as relações entre os espaços e tempos analíticos. Num ensaio uma relação com os mapas, é possível dizer que é fundamental a articulação da pequena escala que permite uma aproximação com o contexto geral coletivo com a grande escala, que permite pensar sobre o contexto mais singular, que se processa diariamente como dinâmica do cotidiano compartido.

$\mathrm{Na}$ espacialidade concreta dos objetos e das ações vividas, se assenta a dimensão "do onde", ou seja, um espaço localizado e objetivado, que o sujeito realiza dialeticamente o referenciamento das aprendizagens, sejam elas espontâneas como no caso daquelas construídas no âmbito familiar, ou as arbitrárias como as oferecidas pela educação escolar. É importante salientar que tanto individualidade quanto coletividade co-implicam (Massey, 2008) em dimensões local-e-global.

As interações entre os objetos e as ações naturais e sociais envolvem sempre uma localização, ou seja, um local onde e como ocorrem os eventos. Essas relações podem ser reais ou virtuais, locais ou regionais, próximas ou distantes, internas ou externas, visíveis ou invisíveis, concretas ou abstratas, objetivadas ou representadas. Há cada vez mais complexidade, velocidade e volatilidade nessas relações que estão situadas em algum e com algum local, o que torna o espaço, elemento constitutivo da vida de todos os sujeitos. É em um local e na relação com outros locais que as interações se realizam. É também, no hoje no agora, que se manifestam essas interações com objetos e ações em diferentes locais e abrangências. Imbricado de historicidade, o cotidiano e o lugar são vividos na grande escala das vivências, e é esse espaço que se impõe como fundamental nas escolhas de cada sujeito e de seus grupos.

Não é difícil relacionar os pensamentos e os movimentos de cada sujeito e de seus grupos com os objetos espaciais suas dimensões, disposições/arranjos e formas. Dizendo de outro modo, não é possível viver nem conceber o dia a dia sem a noção da espacialidade. As decisões diárias, desde a circulação pela cidade, por exemplo, (a pé, bicicleta, carro, ônibus, metrô, trem, helicóptero, barco), relacionam-se com as ofertas objetivadas em meios e vias de transporte de cada local, cada qual com suas proibições e permissões. O vivido, o percebido e o concebido (Lefebvre, 2006) estão sempre referenciados em um local. $\mathrm{O}$ arranjo das coisas e das pessoas em suas dinâmicas interações está em um espaço e mantém com ele relação de interdependência.

Haverá escolhas que não têm relação com a espacialidade? A resposta é não. Em grande parte das situações o sujeito pode eleger movimentos apenas entre as possibilidades dadas. Daí a imprescindibilidade do espaço e do jeito de entendê-lo, seja como linear, alheio e estático ou como resultante dinâmico das decisões individuais e coletivas, no dia a dia. 
Depreende-se que o cotidiano e o lugar servem como categorias para pensar sobre o contexto escolar criado e composto pelos indivíduos, que são sujeitos singulares, que estão sujeitos às políticas públicas. Vale dizer que em grande medida a educação se apresenta como oportunizadora da apreensão de entendimentos outros, contemplando a singularização desconforme e criativa para um melhor viver individual e também para contribuir com o melhor viver com e da humanidade. Essas ponderações conceituais, a seguir, permitem apresentar a problemática focada neste texto, relacionando a individualidade dos sujeitos com a proposição pública de planos generalizantes.

\section{COTIDIANO E O LUGAR NA VIDA DO SUJEITO, SUJEITO ÀS POLÍTICAS PÚBLICAS}

Tendo como pressuposta a espacialidade presente na vida dos sujeitos, as categorias, cotidiano e lugar carregam uma dimensão de concretude e atualidade, por isso, estão aqui apresentadas como artifícios para pensar sobre a individualidade. Esse debate remete inicialmente para análise conceitual de 'lugar' e 'cotidiano'. Em comum, essas categorias tem a centralidade de abranger as relações factuais da práxis de cada pessoa individualmente e nos grupos com os quais interage. Cabe reforçar, que a dimensão da individualidade, aqui pensada na perspectiva de cotidiano e lugar, co-implica em loca-e-global.

O cotidiano e o lugar constituem a dimensão decisiva das aprendizagens que vão sendo construídas pelo sujeito nas interações, uma vez que neles estão os significantes que constituem (sempre provisoriamente) a singularidade de cada sujeito desde a infância. As possibilidades de significação, ou seja, de atribuição de outros sentidos, num movimento dinâmico de aprimoramento das capacidades para o melhor viver, se relacionam, dependem e se manifestam no lugar e cotidiano de cada um. O que e como se aprende, é dependente dos elementos e das ações com os quais se está em interação e as relações de significado que se os atribui (multiescalares). Mas também as mudanças decorrentes do aprendido, se realizam nesses âmbitos sob a forma de significados outros que são construídos, e que, de algum modo modificam a vida real dos sujeitos.

Cotidiano e lugar contem uma dimensão de localidade. Nesse sentido é possível construir um sistema de relações que auxiliam na compreensão desse âmbito dinâmico e inerente a vida. Milton Santos (2010, p. 108-110) chama a atenção para as variações que se processam e se expressam no âmbito do local. Denomina essa dimensão de horizontalidades onde

[...] Todos os agentes são, de uma ou de outra forma implicados, e os respectivos tempos, mais rápidos ou mais vagarosos, são imbricados.

[...] A partir do espaço geográfico cria-se uma solidariedade orgânica, o conjunto sendo formado pela existência comum dos agentes exercendo-se sobre um território comum (Santos, 2010, p. 109).

As relações espaciais a que se refere o pesquisador são configuradas individualmente pelo sujeitos de natureza social (Bakhtin, 2010). Santos (2008b) lembra ainda que "o espaço impõe a cada coisa um conjunto de relações porque cada coisa ocupa um certo lugar no espaço" (p. 172). O cotidiano e o lugar tem assim uma correlação com uma conotação que aproxima do singular, porque carregam dimensões de proximidade, de concretude, de realidade, de relação pessoal e até mesmo presencial. Remete à ação, à oralidade e ao contato vivencial de significados.

A ideia de localidade é no sentido de que é intrincada de instâncias vividas, ou seja, de cotidiano e de lugar. Acerca deles é relevante também esclarecer algumas relações que peculiarizam esses 
âmbitos da vida. Há um limitado consenso ou especialmente há resumida clareza argumentativa do cotidiano como sendo uma das categorias de análise, inclusive e especialmente na Geografia. Algumas vezes, o lugar é até mesmo sugerido para não dizer confundido com a categoria cotidiano. A necessidade desse esclarecimento decorre da urgência do debate da vida diária, não apenas pela direção que considera o espaço como ambiente de identificação e pertencimento do sujeito (que no caso se refere à categoria lugar), mas, pelo percurso que leva em conta os vínculos também efêmeros, mas, necessários e inegavelmente presentes, a que somos diariamente impelidos pela vontade, necessidade ou obrigatoriedade (que se referem ao cotidiano).

A análise traz presente argumentos que se apoiam também em outras áreas do conhecimento, como a Filosofia, a Sociologia e a História, que debatem o cotidiano considerando as vinculações com seus campos. Em comum com a Geografia, tem a centralidade no debate sobre o cotidiano e um modo de explicitação que permite o olhar geográfico porque se pode depreender nas manifestações desses autores, a latente espacialidade.

Estas categorias, que prendem e que seduzem, têm vinculações que são da ordem que Marques (2000) denomina de "tesouro secreto" imbricados do banal e do fantástico, do fatalismo e da serenidade (p. 20) que configuram a constituição da subjetividade singular. Ambos, lugar e cotidiano, pertencem aos plexos tecidos na vida como malha que contem proximidade e intimidade e também como rede de significados que une pontos em diferentes escalas. Física, cognitiva, valorativa e emocionalmente, cotidiano e lugar são interdependentes, dinâmicos e peculiares a cada sujeito que os vivencia.

Mas a categoria lugar pode ser distinguida do cotidiano no sentido de que põe acento no

(...) é o espaço do vivenciado ontem ou hoje, mas com a particularidade de ter identificação e pertencimento com a pessoa. Independentemente da forma como ocorrem os movimentos do sujeito, sempre se trata de um espaço com o qual há ou houve contato direto e concreto (...). É importante lembrar que não é a dimensão ou tamanho da área que contam para conceber lugar, mas de identificação e aprofundamento nas diferentes sensações e experimentações diárias. (...) Lugar é, assim, uma parte do espaço geográfico com o qual temos vínculos afetivos, onde vivemos e interagimos, criando uma paisagem (Andreis, 2012, p. 77).

Nesse sentido, o lugar é todo local com o qual se constrói identificação emotiva. Para compreender essa categoria, cabe um convite ao leitor para uma reflexão sobre quais os locais do passado e do presente com os quais se identifica. O espaço onde vivenciou sua infância ou onde reside atualmente pode ser apreendido como lugar, ou não. Essa compreensão depende das vivências a que o sujeito esteve exposto. Para algumas pessoas esse tempos e espaços podem estar carregados de negatividade, ou melhor, de elementos e de ações desagradáveis e de convivência por obrigatoriedade e necessidade. Nesse caso não são apreendidos como compreensão de lugar. Por outro lado, quando esses ambientes e eventos são apreendidos com sensações e relações agradáveis e que denotam vínculos emocionais constituem-se como lugar. Para outras pessoas esses espaços e tempos podem ser apreendidos apenas como cotidiano.

O cotidiano pode ter uma compreensão associada com lugar. O cotidiano pode ser um espaço de identificação e pertencer ao dia a dia da vida do sujeito, mas, no sentido aqui interpretado, é uma categoria que pode ser peculiarizada fundamentalmente por conter significantes com os quais $o$ sujeito interage independentemente do grau de identificação e pertencimento. 
O local-global vivido pelas relações diretas e indiretas, concretas e abstratas, consciente e inconsciente a que cada um está exposto e em interação, independentemente da identificação e do pertencimento, pode ser mais relacionado com o cotidiano. Constitui-se e é constituído diária e dinamicamente pelo pensar e pelo fazer das pessoas nas relações que estabelecem entre si e com os objetos. Por necessidade e obrigatoriedade, as relações de encontro e confronto que se processam, independentemente da identificação afetiva, ratificando assim, que, não necessariamente, é apreendido como lugar de identificação e pertencimento.

Heller (2008) reconhece que não há uma realidade humana que não esteja, bem ou mal, imbricada e vinculada à realidade do concreto cotidiano ou que não esteja inserida numa cotidianidade. Mesmo que algumas escolhas diárias se baseiem em linhas teóricas ou pensamentos abstratos, ainda assim, "ninguém consegue identificar-se com sua atividade humano-genérica a ponto de poder desligar-se inteiramente da cotidianidade" (id. p. 31). O viver e conceber o local não prescinde o viver e o conceber global. A realização, ou melhor, o enunciado dos sujeitos, compreendido numa aproximação com a perspectiva bakhtiniana (Bakhtin, 2010) como movimento ou ação, se dá em relações produto e produtoras de espaço. Paralelamente, ninguém consegue viver e conceber (em nível do eu individual e do nós genérico) um cotidiano que não seja espacializado, pois, o cotidiano é a "vida do homem inteiro (...). Nela se colocam 'em funcionamento' todos os seus sentidos, todas as suas capacidades intelectuais, suas habilidades manipulativas, seus sentimentos, paixões, ideias, ideologias" (Heller, 2008, p. 31).

O cotidiano é a instância que revela em seu cerne as relações diretas e indiretas, com os quais o sujeito interage de forma dinâmica e complexa, heterogenia e hierarquicamente todos os dias, independentemente do seu grau de consciência ou identificação. O cotidiano segundo Certeau, Giard e Mayol "é o indicador fiel e tagarela" (2005, p. 204) onde os objetos e as são ações compartidos por todos nas interações diárias.

O cotidiano implica em uma dimensão que permite uma análise dos tecidos objetivados e subjetivados do (e entre) o local e global. É a instância constituída pelos objetos e ações naturais e artificiais construídos (e arranjados) sob a direção das pessoas, em grande medida, condicionadas pelas alternativas oferecidas. Chamo a atenção para a concretude do cotidiano, mas, reitero que implica também no que não é visível, como as relações entre os objetos e as pessoas e, também, aquilo que não é consciente, ou melhor, aquilo que não sistematicamente avaliado.

De Certeau, Giard e Mayol qualificam o cotidiano explicando que é

(...) aquilo que nos é dado cada dia (ou que nos cabe em partilha) nos pressiona dia após dia, nos oprime, pois existe uma opressão do presente. Todo dia, pela manhã, aquilo que assumimos, é o peso da vida, a dificuldade de viver, ou de viver nesta ou noutra condição, com esta fadiga, com este desejo (2005, p. 31).

Em suas dinâmicas, todos os dias, rotineiramente e criativamente se processam as relações que envolvem elementos locais, regionais e globais. São diversas as formas e modos dos movimentos interativos que envolvem animais, coisas e pessoas do local e de outros locais. Caracterizam-se por continuidades e descontinuidades, com duração curta ou prolongada em contatos muitas vezes efêmeros que não criam vínculos afetivos. Por opção e por pressão em casa, na rua e no trabalho, se convive e se constrói o cotidiano. O cotidiano não se configura apenas na vivência de um objeto, de uma ação ou de uma pessoa. É o conjunto indissociável e também contraditório onde as interações 
se processam. Não são apenas os objetos e as ações em si, mas, sua historicidade e as relações que entre estes se estabelecem. O cotidiano é difuso, fugidio, assustador, duvidoso, instável, arbitrado, superficial, efêmero, acusatório, paradoxal, dialético, veloz, perverso, espetacular, fluido, fluxo, rotineiro.

O cotidiano compartido entre as mais diversas pessoas "[...] é a base da vida em comum. [...] Cada qual exerce uma ação própria, a vida social se individualiza [...]. É o quadro de uma referência pragmática ao mundo, do qual lhe vêm solicitações e ordens precisas de ações condicionadas mas é também o teatro insubstituível das paixões humanas, responsáveis, através da ação comunicativa, pelas mais diversas manifestações da espontaneidade e da criatividade" (Santos, 2004, p. 322).

As vivências, percepções e concepções são em grande medida influenciadas e pode-se até dizer determinadas pelo arranjo espacial. As escolhas diárias têm relação direta com a composição espacial com a qual se interage. As impressões das temporalidades em cada local e momento dialogam ativamente com o sujeito na produção do espaço. Essas relações diretas e indiretas (concretas e virtuais, próximas e distantes, visíveis e invisíveis, conscientes e inconscientes, perenes e efêmeras) contêm cooperação, conflito ou uso pontual e alheio.

O lugar é peculiar em relação ao cotidiano, também, porque supõe identificação afetiva, o que abrange, em geral, um espaço ou uma ideia mais circunscrita, mas, desencadeia vinculações duradouras. O cotidiano, ao contrário, pode ser compreendido numa dimensão do vivido todos os dias, mas, pode apenas pertencer ao circuito de movimentos e imagens com que o sujeito compartilha e que pode rapidamente esquecer ou simplesmente não gostar (não se identificar, não significar de forma importante ou conscientemente relevante). Com o decorrer do tempo, ao criar vinculações afetivas e de pertencimento, o cotidiano pode vir a se tornar o lugar do sujeito.

O lugar e o cotidiano do sujeito são o habitar do sujeito. Esse habitar é construído e constrói o sujeito que é único e que, compreende-se que se pretenda pela escola, reconstrua originalmente sua singularidade. A pretensão não é, que pela educação escolar, que tem uma conotação coletiva e é sujeita a proposições gerais, o sujeito se torne igual aos grupos com os quais interage. De qualquer modo isso não seria possível, porque, há uma sempre reconfiguração original que se relaciona com o lugar e o cotidiano únicos de cada sujeito.

A espacialidade, numa compreensão que pressupõe temporalidades imbricadas, aqui apresentadas como categorias, cotidiano e lugar, está presente nas vivências e concepções que estão na constituição peculiar de cada sujeito social. E na educação escolar, essas dimensões, que envolvem a individualidade e singularidade dos sujeitos são importantes, porque elas são o sustentáculo das relações de significados que são construídos. Essa problemática move esta discussão, porque, as políticas públicas são planos gerais apresentados pelo poder constituído, em diferentes escalas e instituições de ensino, sejam elas públicas, comunitárias ou privadas.

\section{POLÍTICAS PÚBLICAS PARA SUJEITOS SINGULARES}

A proposição pública de projetos amplos e gerais sugeridos ou apresentados aos sujeitos da escola é uma necessidade de Estado. Especialmente em um Estado que se apresenta como republicano, ou seja, que apreende a coisa pública como originária e destinada para todos os sujeitos que estejam 
envolvidos naquele contexto territorial. Geralmente sob a denominação de diretrizes sugestivas, são propostas gerais em relação às quais é importante lembrar que trazem "presente as estruturas de poder e de dominação, os conflitos infiltrados por todo tecido social e que têm no Estado o lócus da sua condensação" (Azevedo, 1997, p. 5).

As políticas públicas compreendem o conjunto das ações empreendidas pelo Estado no município, estado e federação, decorrentes das concepções elaboradas pelos grupos gestores. Podem representar uma proposição que tem uma pretensão e uma abrangência imediata ou mediata espacial e temporalmente. No primeiro caso aproxima-se de uma estratégia como política de governo e no último, aproxima-se de uma política de Estado. Podem ainda, as políticas públicas, ser implementadas a partir de imposições dos gestores ou advir da demanda social. E, para tensionar a reflexão na aporia entre o sujeito singular constituindo-se no lugar e cotidiano, e a política pública coletiva e globalizante, realizo algumas aproximações conceituais com Milton Santos (2010) e Boaventura Santos (2007).

As verticalidades podem ser compreendidas como as relações entre macroatores, macroempresas, que, como conjunto de adequado as tarefas produtivas hegemônicas, atuam numa solidariedade do tipo organizativo-administrativa onde predominam escolhas que tem agentes externos que tomam as decisões de regulação. Manifestas pelo global, que permite remeter a ideia de um pensamento único (que pode correr o risco de se apresentar como fatalismo, perversidade e fabulismo), a verticalidade é compreensível, em grande medida na dimensão da impessoalidade. (SANTOS, 2010, p. 105-108). "Cada um deve adaptar comportamentos locais aos interesses globais que estão sempre mudando" (idem, p. 106). Na perspectiva da dimensão do coletivo, o Estado tem um papel que pode se caracterizar pelo

[...] controle a ação explícita ou dissimulada do Estado, em todos os seus níveis territoriais. Tratase de uma regulação frequentemente subordinada, porque, em grande número de casos, destinada a favorecer os atores hegemônicos (Santos, 2010, p. 106).

Uma integração, em grande medida, dependente, dominadora e alienadora que se aproxima de uma ação empresarial. Uma gestão em um modelo hegemônico planejada para ser na ação individual, indiferente ao entorno onde quer se fazer presente, ou seja, no cotidiano e lugar dos sujeitos (Santos, 2010, p. 107).

Boaventura Santos (2007) salienta outra relevante análise sobre essas percepções como monopólios modelados em formas monocultoras imbricadas de estruturas de pensamento hegemônicas. $\mathrm{O}$ coletivo é o geral e tem dimensão de abstrato, distante, de representado e representante, de relações impessoais ou de coisas do outro e de ausências.

Se o coletivo, implicado em uma ideia de todo e de global, como política pública, pouco se esforça para reconhecer as singularidades, é por que pode as estar pensando apenas a partir de pressupostos da instância generalizante, para (em alguns casos) posteriormente, abrir para à audição do peculiar. Apostando-se exaustivamente na criação de identidade do conjunto, exclusivisa-se o coletivo e parte-se desse geral para abrir às peculiaridades. Uma mera simulação artificial e superficial de exercício democrático, cujos efeitos são inócuos. Um sufoco que pode levar ao abandono ou rechaço das políticas públicas de Estado. Lugar e cotidiano são constituídos por sujeitos singulares, que significarão de um modo exclusivo as proposições gerais. Nessa análise, os planos públicos, tendem a ser, entendidos de modo diferente por cada grupo, ou ainda, podem ser compreendidos de 
modo distorcido da proposição inicial, apresentada pelo Estado. Correm o disco também de serem simplesmente rechaçados.

A ideia de totalidade é reducionista e em grande medida impõe um desperdício de experiências (Santos, 2007). Com sentidos que não contemplam os significantes dos sujeitos singulares em seus grupos locais (professores, alunos), as políticas públicas como um todo, acabam sendo, em grande medida, incompreendidas. Sua apreensão, não se realizando como uma ressignificação, porque tem relação com os significantes peculiares e individuais de cada sujeito, torna-se inócua.

Arendt (1971) chama a atenção ainda, para outra questão latente ao discutir o que é política. Trata-se das formas de organização que a experiência humana vem demonstrando:

[...] A pergunta atual surge a partir de experiências bem reais que se teve com a política, ela se inflama com a desgraça que a política causou em nosso século, e na maior desgraça que ameaça resultar delas. Por conseguinte, a pergunta é muito mais radical, muito mais agressiva, muito mais desesperada: tem a política algum sentido ainda? (Arendt, 1971, p.14).

Ao afirmar que a questão atual está além do que é a política que teria uma resposta na liberdade, Arendt (1971) lembra que as experiências de exercício da política, pretensamente baseada no pressuposto da liberdade, exigem que fiquemos atentos aos riscos dos absolutismos. Um entendimento de política como abertura ao debate, ao enunciado e a escuta dos sujeitos espaciais.

O que Santos (2007) denomina de monoculturas, como homogenizações e monopolizações que se sobrepõe as ecologias que a sociedade composta de diferentes contém, dificultam a emergência do peculiar e singular, que poderia enriquecer a humanidade, pois acaba ocorrendo desperdício de experiências. Um sentido que Raffestin (1993) afirma ser usado pelo Estado como instrumento de ordem e não de regulação, considerando "certo que o Estado persegue uma lógica da unidade e da uniformidade, mas por isso mesmo substitui a diversidade pela generalidade" (p. 182).

As políticas públicas como intervenção por parte de um Estado complexo pode hipertrofiar a sociedade e hipertrofiar-se como organismo. Não se trata da defesa de um Estado mínimo, que interessa á economia globalizante, mas, de uma preocupação que coloco o sujeito, o humano, no centro das escolhas político-institucionais. O que questiono, é o caráter normativo de políticas públicas, que estejam articuladas com um mundo que tem como base e foco uma compreensão centrada na economia. Gestadas fora dos sujeitos aos quais pretende atingir, ouve apenas as vozes fortes que se impõe porque, porque possui instrumentos fortes para fazer-se ouvir e se objetivar. Coloca-se de frente e de encontro com o outro que pode ser simplesmente desconsiderado e prejudicado.

Cada coisa e cada pessoa são únicas, inimitáveis, incomparáveis e o arranjo em cada um é peculiar. Então a possibilidade para a questão posta, frente à necessidade de convívio entre o individual singular e o público coletivo, reside em uma articulação entre as dimensões local e global.

Pode haver, por exemplo, movimentos para escuta da proposição do local para, a partir daí construir o global. Chamo a atenção para a forma como se realizaria esse reconhecimento dos locais. Isso porque, não se trata apenas de mera contemplação de espaço/tempo formal para a audição dos sujeitos. Uma escuta desse porte se torna descompromissada, porque, não tem como pressuposta a constituição intersubjetiva dos sujeitos. 
Entendo que é importante essa consideração do todo, porém, se torna vazia se não ocorrer identificação daqueles que em dimensão local irão concretamente trabalhar o ato educativo, ou seja, aqueles que irão por em movimento a política pública, quer dizer, em educação um protagonismo especialmente dos professores. É a dimensão do local que contém os significantes que podem provocar a atribuição de sentidos outros, modificando posturas. Por isso é fundamental tomar o lugar e o cotidiano, como bases para qualquer pretensão generalizante em educação.

Uma vez que "o mundo da vida precede aos indivíduos" (Marques, 2000, p. 19) e a percepção das coisas, das pessoas e das ações é peculiar em cada sujeito, daí que urge considerar as possibilidades no contexto das determinações globalizantes:

À base da experiência do gênero humano se inserem os sujeitos em seu mundo de vida e o reconstroem ao nele se relacionarem entre si e com suas objetivações de maneira ainda não tematizada, isto é, não fracionada pelas abstrações discursivas, pano de fundo e suporte, no entanto, por ela supostos (Marques, 2000, p. 19).

O aprender e o que Marques (2000) denomina de "concritiatividade" como possibilidade de reconstrução aberta à inventividade individual, depende do contexto cotidiano espacializado para se efetivar. A peculiarização de cada pessoa relaciona-se diretamente com a significação que atribuirá às interações a que se expõe fora e dentro da escola. Dizendo de outro modo, os conhecimentos de toda ordem "emergem do interior da experiência vivida no espaço particularizado [...]" (Marques, 2000, p.20). As possibilidades de individuação estão nos objetos e ações, pois é,

No cotidiano brotam as dúvidas, os questionamentos, os problemas de que se originam as ciências sempre necessitadas de renovação por sua absorção nas práticas de cada dia, desafiadoras das elucubrações teóricas de um passado, embora recente (Marques, 2000, p.20).

$\mathrm{O}$ fato de que o lugar e o cotidiano dos sujeitos escolares compreenderem a "vida de todo dia, fragmentada e plural, subterrânea e tenaz" (Marques, 2000, p. 20), abre para repensar sobre as possibilidades das conexões com as políticas públicas em educação, que são proposições intencionais apresentadas pelo poder constituído.

As múltiplas dimensões de uma globalidade exacerbada e as generalidades da cultura que implicam na dinâmica dos objetos e das ações, são apreendidas de modo específico por cada indivíduo e local. As relações que cada pessoa realiza ao se encontrar/confrontar com um novo conceito é específica, única, ou melhor, dotada de exclusividade e originalidade.

As políticas públicas não é necessariamente uma compreensão organizacional objetivada sob a forma de parâmetros ou normas resultantes de construção em conjunto com o social. Pode se configurar como uma proposição para, que tem como destino, um social. Isso exigiria reconhecer que política deva ser uma construção entre os as pessoas e não para as pessoas. Exigiria também, entender que é política é um conceito que difere da compreensão como instrumento usual e burocrático da coisa pública, e que deve, se abrindo à construção com os sujeitos singulares, abarcar a organização da vida das pessoas. Se assim não se objetivar, a política pública pode chegar ao sujeito como cultura de massa, utilitária e externa.

Se a forma de enunciar leva em conta o contexto do local e do momento em que se processa esse encontro/confronto com a política pública, os sujeitos da escola vão estabelecendo vinculações com os seus significantes que por sua vez tem relação com sua experiência. Assim, cada generali- 
zação normativa, por exemplo, sofrerá um arranjo cognitivo único, específico e momentâneo. Serão construções conjuntas que envolverão o individual e o coletivo. É importante lembrar que mesmo as conexões em cada local serão distintas e originais para cada sujeito envolvido, mas, se deles partir, há uma identificação, um reconhecimento maior.

Nesse processo de reconstrução de significados é fundamental dar a palavra e não apenas trazer a palavra como verdade peremptória apresentada para sujeitos. A pretensão de mera repetição além de ilusória é simplesmente infrutífera. E, é graças a essa impossibilidade, a permanente reconstrução da tradição. Dessa condição depende a 'garantia' da manutenção da desigualdade, ou melhor, da não homegeniedade, ou dizendo ainda de outro modo, a possibilidade de criatividade do humano.

Tendo defendido o lugar e cotidiano, mesmo que como construções intersubjetivas das compreensões individuais, me obrigo ao reconhecimento de que não é uma tarefa fácil abrir à mediação entre essas singularidades e a importante organização geral, que se realiza em grande medida como política pública. Uma vez que ela é necessária para permitir uma convivência em sociedade, desde que, como organizadora das diversidades absolutas. O que não se admite é a abslolutização das políticas públicas.

\section{ENCAMINHANDO A DISCUSSÃO}

Em educação é importante ter presente que as políticas públicas são generalizações constituídas numa percepção em grande medida hierarquicamente vertical e homogeneizante. Necessárias para organizar a coletividade, carregam um tom globalizante. Dotadas de amplitude, distância, imperiosidade, fabulosidade e perversidade, em grande medida, podem simplesmente achatar o singular e o local.

O sujeito se constitui pela linguagem a que se expõe no decorrer da vida e é por meio dela que manifesta e reconstrói suas capacidades. Também, os entendimentos humanos são resultantes de acordos provisórios aceitos como válidos pelos grupos. E, nesse sentido, discutir o lugar e o cotidiano é fundamental no contexto das proposições de políticas públicas em educação. Isso porque, o mundo concreto da vida de um grupo social inclui pré-condições objetivamente estabelecidas e um leque das possibilidades (Marques, 2000, p. 54).

$\mathrm{Na}$ experiência como professora-pesquisadora posso testemunhar inúmeras tentativas de implementação de políticas públicas. Muitas vezes são simplesmente ignoradas, tornadas sem efeito. Elas são e continuam vazias e ineficazes, porque, são advindas de um contexto que contempla visões externas que não atravessam os sujeito àqueles se quer participantes.

A contextualização se realiza pela implicação do sujeito. Nunca como um somatório de ideias e coisas. Sempre como processo de reconstituição original que pressupõe um sujeito que se reconheça como pertencente. Seu aprender é sempre com e no cotidiano e lugar. Por isso um plano público de educação se realizaria, numa aproximação com o conceito de cooperativo. Esse conceito remete a compreensão de participação que contém imbricada a identificação e pertencimento do sujeito singular na constituição do todo coletivo. Isso exige também do sujeito o que Arendt (2002) denomina de "capacidade de discernimento". Uma capacidade de agregar o isolado ao geral que a cada um corresponde e sobre o qual se chegou a um acordo. 
Uma política pública para um sujeito singular não se contrapõe às possibilidades educativas escolares. Ao contrário, contribui para a educação como constituição de um sujeito autônomo e emancipado, porque e desde que, construa compreensões pontuando relações escalares, local e global, que oportunizem a ressignificação do mundo da vida.

Tudo o que fazemos está situado na relação com os objetos que nos cercam (Santos, 2008a) e, por isso, lugar e cotidiano se configuram como dimensões centrais. Servem como artificio para pensar a relação entre a individualidade e as políticas públicas que implicam em coletividade, porque, das margens, onde residem às singularidades, é possível enxergar diferente. No contexto atual de dificuldade de implementação de políticas públicas, uma vez que o sujeito não se se sente por elas atravessado, o desafio posto, está em aproveitar suas experiências, e, convidando-o ao diálogo, reconhecê-lo e não apenas tomá-lo objeto de uma meta interessada em uma convivência coletiva.

\section{REFERÊNCIAS}

Andreis, Adriana Maria. Ensino de Geografia fronteiras e horizontes. Porto Alegre: Compasso Lugar Cultura, 2012.

Arendt, Hannah. O que é politica? Rio de Janeiro: Bertrand Brasil, 2002.

Azevedo, Janete M. Lins de. A educação como política pública. Campinas: Editora Autores Associados, 1997.

Bakhtin, Mikhail. Para uma filosofia do ato responsável. São Carlos: Pedro \& João editores, 2010. . Marxismo e filosofia da linguagem. São Paulo: Hucitec, 2004.

De Certeau, Michel de; Giard, Luce; Mayol, Pierre. A Invenção do Cotidiano, Morar e Cozinhar. Petrópolis: Vozes, 2005.

Lefebvre, Henri. A produção do espaço. Tradução Doralice Barros Pereira e Sergio Martins (do original: La production de l'space. 4 ed. Paris: Edition Anthropos, (2000) Belo Horizonte: no prelo, 2006. Disponível em: <http://www.mom.arq.ufmg.br/mom/arq_interface/1a_aula/A_producao_do_espaco.pdf>. Acesso em: 10 mar. 2013.

Marques, Mario Osorio. Aprendizagem na mediação social do aprendido e da docência. Ijuí: Editora UNIJUí, 2000.

Merleau - Ponty, M. Fenomenologia da percepção. Rio de Janeiro: Livraria Freitas Bastos S.A., 1971.

Massey, Doreen. Pelo espaço. Rio de Janeiro: Bertrand Brasil, 2008.

Raffestin, Claude. Por uma geografia do poder. São Paulo: Ática, 1993. 
Santos, Boaventura de Sousa. Renovar a Teoria crítica e reinventar a emancipação social. São Paulo: Boitempo, 2007.

Santos, Milton. Por uma outra globalização: do pensamento único à consciência universal. $6^{\mathrm{a}}$ ed. Rio de Janeiro: Record, 2010.

. Metamorfoses do espaço habitado. São Paulo: EDUSP, 2008a.

. Por uma geografia nova. São Paulo: EDUSP, 2008b.

. A natureza do Espaço: Técnica e Tempo, Razão e Emoção. $4^{\mathrm{a}}$ ed. São Paulo: Editora da Universidade de São Paulo, 2004.

Stam, Robert. Bakhtin: da cultura literária à teoria de massa. São Paulo: Ática, 1992.

Articulo recibido en febrero 15 de 2013 - Aprobado en marzo 30 de 2013 